\title{
TEOR E ACÚMULO DE NUTRIENTES EM GRÃOS DE FEIJÃO COMUM EM SEMEADURA DIRETA, SOB DÉFICIT HÍDRICO
}

\section{JOSÉ JOAQUIM DE CARVALHO'; JOÃO CARLOS CURY SAAD ${ }^{2}$; ALEFE VIANA SOUZA BASTOS ${ }^{3}$; SARA SANTIAGO NAVES ${ }^{4}$; FREDERICO ANTÔNIO LOUREIRO SOARES ${ }^{5}$ E VITOR MARQUES VIDAL ${ }^{6}$}

\footnotetext{
${ }^{1}$ Tecnólogo em irrigação e drenagem, Pós-doutorando, Instituto Federal Goiano - Câmpus Rio Verde - GO., josejoaquimcarvalho@yahoo.com.br

${ }^{2}$ Engenheiro agrônomo, Prof. Doutor, UNESP - Câmpus de Botucatu , Botucatu - SP., joaosaad@fca.unesp.br

${ }^{3}$ Graduando em Agronomia, Instituto Federal Goiano - Câmpus Rio Verde - GO., alefe_viana@hotmail.com

${ }^{4}$ Graduanda em Agronomia, UFG - Câmpus Samambaia - GO., saradeescorpiao@yahoo.com.br

5 Engenheiro agrônomo, Prof. Doutor, Instituto Federal Goiano - Câmpus Rio Verde - GO., fredalsoares@hotmail.com

${ }^{6}$ Engenheiro agrícola, Mestrando em ciências agrárias, professor, Instituto Federal Goiano - Câmpus Rio Verde -GO., vmarquesvidal@gmail.com
}

\section{RESUMO}

O feijão comum possui notória importância socioeconômica, constitui uma das mais importantes fontes proteicas da dieta brasileira e juntamente com o arroz, proporciona uma dieta mais vantajosa e equilibrada em termos de aminoácidos. O objetivo desse trabalho foi avaliar o efeito das combinações de diferentes reposições hídricas nas fases vegetativa - I e reprodutiva - II, durante o ciclo do feijoeiro IAC Alvorada, e comparar o teor nutricional dos grãos. Foi utilizado o delineamento em blocos casualizados, com quatro repetições em fatorial $4 \times 4$, sendo quatro níveis de déficit hídrico 100, 80, 60 e 40\% da evapotranspiração da cultura $(\mathrm{ETc})$ e os mesmos níveis foram repetidos em duas fases de desenvolvimento da cultura do feijão ( fases I e II). Cada parcela possuía as dimensões de $4 \mathrm{~m}$ x 1,8 m, totalizando $7,2 \mathrm{~m}^{2}$. A semeadura realizou-se em abril e maio de 2010 e 2011 , no espaçamento de $0,45 \mathrm{~m}$. Inicialmente irrigou-se pelo sistema aspersão convencional em um período de 60 minutos diariamente, posteriormente o sistema adotado foi por gotejamento, conforme cada tratamento de restrição hídrica. Avaliaram-se os teores nutricionais de macro $(\mathrm{N}, \mathrm{P}, \mathrm{K}, \mathrm{Ca}$, $\mathrm{Mg}$ e $\mathrm{S}$ ) e micronutrientes ( $\mathrm{B}, \mathrm{Cu}, \mathrm{Fe}, \mathrm{Mn}$ e $\mathrm{Fe}$ ). A interação entre as lâminas nas fases I e II influenciou nos teores de micronutrientes $\mathrm{Fe}$ e $\mathrm{S}$ em grãos de feijão. Houve aumento dos teores de $\mathrm{Fe}$ e diminuição dos teores de $\mathrm{Cu}, \mathrm{Mn}$ e $\mathrm{B}$ com a deficiência hídrica em uma das fases. Os macro e micronutrientes mais extraídos foram N, P, K, Fe, B e Mn. O N e o P são os nutrientes exportados em maior quantidade pelos grãos.

Palavras-chave: Phaseolus vulgaris, lâminas de irrigação, componentes de produção

\section{INTRODUÇÃO}

O feijão comum Phaseolus vulgaris L, ocupa lugar de destaque na agricultura brasileira, sendo caracterizado como forte produto no mercado interno, com grãos que representam uma importante fonte de proteínas e minerais na dieta da população, além de possuir notória importância socioeconômica.

A proteína do feijão é rica no aminoácido essencial lisina, porém pobre nos aminoácidos sulfurados, metionina e cisteína, essenciais ao homem. Já os cereais são pobres 
em lisina, mas ricos em aminoácidos sulfurados, o que torna a tradicional dieta brasileira, arroz com feijão, complementar em termos de aminoácidos essenciais. Por isso, a combinação com cereais se faz necessária, para que se obtenha uma dieta com conteúdo de aminoácidos mais adequados aos requisitos nutricionais da espécie humana.

A maioria das cultivares de feijão utilizadas no Brasil apresenta de 20 a $25 \%$ de proteína (Borén e Carneiro, 2008), sendo este utilizado como alternativa em substituição a carnes e outros produtos proteicos (Rios et al., 2003). Para tanto, a obtenção de cultivares com elevado potencial produtivo e adaptadas ao ambiente de cultivo, juntamente aos sistemas conservacionista de manejo de solo e colheita mecanizada, devem estar aliadas à nutrição mineral adequada e equilibrada.

Dentre os nutrientes essenciais ao ser humano, destacam-se: proteínas, ferro, cálcio, magnésio, zinco, vitaminas (principalmente do complexo B), carboidratos e fibras. Com relação aos nutrientes minerais, os grãos de feijão são ricos, principalmente, em potássio (25$30 \%$ do conteúdo total de minerais), fósforo (cerca de $0,4 \%$ ), ferro (cerca de $0,007 \%$ ), cálcio, zinco e magnésio (Araújo et al., 1996).

Quanto à semeadura, as épocas recomendadas concentram-se, basicamente, em três períodos: cultivo das "águas", de setembro a dezembro, cultivo da "seca" ou safrinha, de janeiro a março e cultivo de "outono-inverno" ou terceira época, de abril a julho (Barbosa \& Gonzaga, 2012). Geralmente, o feijão é cultivado em sistemas solteiro ou consorciado com outras culturas.

O nitrogênio é o nutriente mais utilizado para o feijoeiro e tem influência significativa na produtividade (Silva et al., 2006). O cálcio tem participação na divisão e na elongação celular, com função cimentante, ligando uma célula à outra, na forma de pectato de cálcio, melhorando a qualidade dos frutos e o pegamento das floradas, atuando na germinação do grão de pólen e no crescimento do tubo polínico. O boro atua na divisão e na diferenciação celular, no metabolismo e no transporte de carboidratos e diversos outros processos (Coetzer et al., 1990). Pastorini et al. (2000), relatam que o fósforo é o nutriente que tem proporcionado as maiores e mais frequentes respostas, sendo que sua baixa disponibilidade no solo afeta negativamente o crescimento das plantas e sua produção.

A tolerância à deficiência hídrica é uma característica importante em qualquer cultivo, principalmente no feijoeiro, tornando-se possível a sua produção em extensas áreas. A maneira como a deficiência hídrica se manifesta na planta do feijoeiro é bastante complexa, pois afeta praticamente todos os processos do crescimento, sendo que, os prejuízos causados dependem da duração, do tipo de estresse, da severidade e do estádio de desenvolvimento da planta em que ocorre.

O objetivo deste trabalho foi avaliar o acúmulo de nutrientes em grãos da cultivar cv. IAC Alvorada, em resposta aos tratamentos com deficiência hídrica em duas fases fenológicas durante o ciclo do feijoeiro.

\section{MATERIAL E MÉTODOS}

O experimento foi conduzido numa área de $1.600 \mathrm{~m}^{2}$ no ano de 2010 e 2011 , em sistema de semeadura direta durante o inverno, na Fazenda Experimental Lageado do Departamento de Engenharia Rural da Faculdade de Ciências Agronômicas - UNESP, Campus de Botucatu, na região centro oeste do Estado de São Paulo que se encontra a $22^{\circ} 51^{\prime}$ de latitude sul, 48 $26^{\prime}$ ' de longitude oeste de Greenwich, e altitude de 786 metros. 
De acordo com Cepagri (2010), pela classificação de Koeppen, o tipo climático é o Cwa, caracterizado como clima temperado quente (mesotérmico) com chuvas no verão e seca no inverno. O período seco compreende os meses de abril a agosto, e a estação chuvosa compreende os meses de setembro a março, sendo o mês de janeiro o mais chuvoso, com uma pluviosidade total anual média de $1.314 \mathrm{~mm}$ e temperatura média mensal de $19,4^{\circ} \mathrm{C}$.

Os valores médios das características químicas do solo, na camada de 0-0 a 0,2 m, antes da instalação do ensaio, foram de: 4,7 de $\mathrm{pH}$ em $\mathrm{CaCl}_{2} ; 21,0 \mathrm{~g} \mathrm{dm}-3$ de matéria orgânica; 4,7 $\mathrm{mg} \mathrm{dm}^{-3}$ de Presina; 1,$7 ; 13 ; 7 ; 30$ e 1 mmolc dm$^{-3}$, respectivamente, de $\mathrm{K}, \mathrm{Ca}$, $\mathrm{Mg}, \mathrm{H}+\mathrm{Al}$ e $\mathrm{Al}$, e 41,5\% de saturação por bases (V\%), 0,16;11,55;38,5;13,85;1,15 mg dm ${ }^{3}$ de B, Cu, Fe, Mn e Zinco, respectivamente. Obteve-se a análise granulométrica do solo, com valores de 42,31, 44,47 e 13,21\% de areia, silte e argila, respectivamente e a densidade do solo pela metodologia do torrão parafinado, com valores de 1,35 e $1,38 \mathrm{~g} \mathrm{~cm}^{-3}$ para 0 a $15 \mathrm{~cm}$ e 15 a $30 \mathrm{~cm}$ de profundidade, respectivamente.

No segundo ano, na camada de 0-0 a 0,2 m, antes da instalação do ensaio, os valores foram de: 4,85 de $\mathrm{pH}$ em $\mathrm{CaCl}_{2} ; 24,0 \mathrm{~g} \mathrm{dm}^{-3}$ de matéria orgânica; $24 \mathrm{mg} \mathrm{dm}{ }^{-3}$ de Presina; 1,9; 29; 14; 40 e 1 mmolc dm ${ }^{-3}$, respectivamente, de $\mathrm{K}, \mathrm{Ca}, \mathrm{Mg}, \mathrm{H}+\mathrm{Al}$ e Al, e $51 \%$ de saturação por bases (V\%); 0,28; 11,9; 43,5; 16,5; 1,2 $\mathrm{mg} \mathrm{dm}^{-3}$ de B, Cu, Fe, Mn e Zinco, respectivamente. A densidade do solo pela metodologia do torrão parafinado foi de 1,39 e $1,41 \mathrm{~g} \mathrm{~kg}^{-1}$ para as camadas de 0 a $15 \mathrm{~cm}$ e de 15 a $30 \mathrm{~cm}$ de profundidade, respectivamente. As análises citadas foram efetuadas quatro meses antes da instalação do experimento no campo. As coletas dos torrões foram realizadas com o auxílio de um enxadão e durante o procedimento procurou-se evitar a compactação do mesmo. As determinações das análises químicas e físicas, seguiram as metodologias de Raij et al. (2001) e EMBRAPA (1997).

O solo da área experimental é classificado como Nitossolo Vermelho distroférrico, textura argilosa (EMPRAPA, 2006).

Foi realizada a calagem do solo, manualmente na superfície do solo no primeiro e segundo ano, com dosagens de 1,6 e 1,9 Mg, respectivamente, aos 90 dias antes do plantio, utilizou-se calcário dolomítico, com PRNT de 90\%, de modo elevar a 70\% o índice de saturação por bases (V\%) ao nível adequado à planta, além de neutralizar os efeitos nocivos do alumínio.

A cultivar utilizada foi a IAC - Alvorada do grupo carioca, com hábito de crescimento indeterminado tipo III e porte semi-prostado. A semeadura direta foi realizada, em 09 de abril de 2010 e 10 de maio de 2011, respectivamente, no espaçamento de 0,45 entre linhas e com 13 sementes por metro, de modo a obter uma densidade final de 200.000 a 240.000 plantas ha ${ }^{-}$ 1. Utilizou-se semeadora-adubadora, modelo exacta air JM 2980 PD Jumil. A adubação de plantio foi baseada na análise química do solo, sendo adicionados 321 e $145 \mathrm{~kg}$ ha-1 de adubo granulado na formulação 8-28-16+zinco e $70 \mathrm{~kg}$ de $\mathrm{N}$ aplicado em cobertura e dividido em duas aplicações, a fim de se obter uma produtividade de 2,5 a 3,5 Mg.

A parcela experimental constitui-se de uma área total de 7,2 $\mathrm{m}^{2}(4 \mathrm{~m} \times 1,8 \mathrm{~m})$, com quatro linhas de feijão.

O espaçamento entre blocos foi de $2 \mathrm{~m}$ e entre as parcelas, de $1,5 \mathrm{~m}$. Para efeito de avaliação, as linhas externas de cada parcela foram consideradas como bordadura, além das duas extremidades de cada parcela, totalizando $1 \mathrm{~m}$.

A diferenciação dos tratamentos, quanto à irrigação, teve início ao nono dia após a semeadura, conforme os tratamentos. Anteriormente foram feitas irrigações em todo o experimento, utilizando-se o sistema de aspersão convencional. A primeira fase (I) teve início quando a planta encontrava-se no estádio $V_{2}(22$ DAE) ao florescimento (40 DAE). A 
segunda fase teve início no florescimento (40 DAE) indo até a maturação fisiológica dos grãos (60 DAE).

O delineamento experimental utilizado foi o de blocos casualizados, com quatro repetições em esquema fatorial $4 \times 4$. Os fatores utilizados foram 4 níveis de déficit hídrico $(100 \%, 80 \%, 60 \%$ e $40 \%$ da evapotranspiração da cultura) aplicados em duas fases durante o ciclo (Vegetativa - I, Reprodutiva -II). Os mesmos níveis na fase I, foram repetidos na fase II. Para compor os tratamentos, variou-se a lâmina de irrigação e o período de aplicação.

O sistema de irrigação adotado foi o de gotejamento, utilizando-se mangueiras gotejadoras com espessura da parede de 625 micra, possuindo um gotejador labirinto tipo plano, espaçados de $20 \mathrm{~cm}$ entre si, com vazão de 7,5 L/h/m na pressão de $100 \mathrm{kPa}$ e expoente da equação de vazão do emissor (x) igual a 0,461. As linhas laterais de irrigação foram distribuídas no espaçamento de $0,45 \mathrm{~m}$, entre as linhas do feijoeiro, as quais formavam uma faixa contínua molhada na área útil da parcela.

A capacidade de armazenamento de água do solo foi de 19,8 mm, para uma profundidade efetiva de solo de $30 \mathrm{~cm}$. Sendo necessárias 1,15 horas de irrigação para atingir a capacidade de campo, com uma eficiência do sistema de $90 \%$.

O manejo das irrigações foi baseado no cálculo da evapotranspiração de referência (Eto) a partir de dados de evaporação do tanque Classe $\mathrm{A}$, situado na Estação Agroclimatologia da FCA-UNESP, a cerca de $150 \mathrm{~m}$ de distância do local do experimento e corrigido pelo coeficiente de correção (Kp) conforme (Allen et al., 1998).

$\mathrm{O}$ tratamento $\mathrm{T}_{16}$ foi mantido como referencial sem restrição de água, tanto na fase inicial quanto na fase reprodutiva. Com as combinações, os demais tratamentos tiveram redução da lâmina em umas das duas fases (I e II).

No campo, a lâmina de água aplicada em cada parcela foi controlada em função do tempo, de acordo com a vazão dos emissores, utilizando-se registros e cronômetro. Diariamente determinou-se o tempo de irrigação para a parcela referência, e, posteriormente, às lâminas com as reduções de $80 \%, 60 \%$ e $20 \%$ referentes às fases I e II.

O florescimento pleno da cultura ocorreu 41 DAE e o ciclo teve a duração de 107 dias para o T16, com redução para os demais tratamentos avaliados comparativamente.

Uma amostra foi obtida de cada parcela, tendo como objetivo, obter o teor nutricional de macronutrientes $(\mathrm{N}, \mathrm{P}, \mathrm{K}, \mathrm{Ca}, \mathrm{Mg}$ e $\mathrm{S})$ e micronutrientes $(\mathrm{B}, \mathrm{Cu}, \mathrm{Fe}, \mathrm{Mn}$ e $\mathrm{Zn})$ após a colheita . Os grãos em cada parcela foram secos em estufa com circulação forçada de ar a 60$70{ }^{\circ} \mathrm{C}$, até atingir massa constante, e, em seguida, foram moídos e submetidos à análise, conforme metodologia de Malavolta et al. (1997).

Foi realizada análise de variância com aplicação do teste de Tukey ao nível de 5\% de significância pelo programa Sisvar 5.0.

\section{RESULTADOS E DISCUSSÃO}

As lâminas de irrigação aplicadas, somando-se as precipitações pluviométricas efetivas que ocorreram durante o ciclo do feijoeiro nas fases I e II, corresponderam a um valor total de $191,22 \mathrm{~mm}$ e $217,99 \mathrm{~mm}$ no primeiro e segundo ano, respectivamente. Verificou-se que as lâminas aplicadas nas fases I e II foram maiores no ano agrícola de 2011, em comparação ao ano de 2010. As lâminas aplicadas em cada fase, em cada tratamento, estão descritos na Tabela 1. 
Tabela 1. Lâminas de irrigação em $\mathrm{mm}$, da emergência ao pleno florescimento - I, e do florescimento a maturação - II, e a lâmina total (Irrigação e Precipitação pluvial), para o ano de 2010 e 2011.

\begin{tabular}{ccccc|cccc}
\hline \multicolumn{7}{c}{ Lâmina em (mm) nas fases I, II; e I + II + precipitação efetiva (Pe). } \\
\hline Fases & I & II & I + II & I $_{+}$II + P & I & II & I + II & $I_{+}$II $_{+}$P \\
\hline Trat. & \multicolumn{7}{c}{2010} & \multicolumn{3}{c}{2011} & \\
\hline T1 & 26,42 & 44,31 & 70,73 & 85,11 & 32,02 & 49,24 & 81,23 & 96,06 \\
T2 & 26,42 & 66,47 & 92,89 & 107,27 & 32,02 & 73,86 & 105,88 & 120,71 \\
T3 & 26,42 & 88,63 & 115,05 & 129,43 & 32,02 & 98,40 & 130,42 & 145,25 \\
T4 & 26,42 & 110,79 & 137,21 & 151,59 & 32,02 & 123,10 & 155,12 & 169,95 \\
T5 & 39,63 & 44,31 & 83,94 & 98,32 & 48,08 & 49,24 & 97,32 & 112,15 \\
T6 & 39,63 & 66,47 & 106,10 & 120,48 & 48,08 & 73,86 & 121,94 & 136,77 \\
T7 & 39,63 & 88,63 & 128,26 & 142,64 & 48,08 & 98,40 & 146,48 & 161,31 \\
T8 & 39,63 & 110,79 & 150,42 & 164,80 & 48,08 & 123,10 & 171,18 & 186,01 \\
T9 & 52,84 & 44,31 & 97,15 & 111,53 & 64,05 & 49,24 & 113,29 & 128,12 \\
T10 & 52,84 & 66,47 & 119,31 & 133,69 & 64,05 & 73,86 & 137,91 & 152,74 \\
T11 & 52,84 & 88,63 & 141,47 & 155,85 & 64,05 & 98,40 & 162,45 & 177,28 \\
T12 & 52,84 & 110,79 & 163,63 & 178,01 & 64,05 & 123,10 & 187,15 & 201,98 \\
T13 & 66,05 & 44,31 & 110,36 & 124,74 & 80,06 & 49,24 & 129,30 & 144,13 \\
T14 & 66,05 & 66,47 & 132,52 & 146,90 & 80,06 & 73,86 & 153,92 & 168,75 \\
T15 & 66,05 & 88,63 & 154,68 & 169,06 & 80,06 & 90,40 & 170,46 & 185,29 \\
T16 & 66,05 & 110,79 & 176,84 & 191,22 & 80,06 & 123,10 & 203,16 & 217,99 \\
\hline T1
\end{tabular}

Nota: *Pe -Precipitação pluvial efetiva $(2010=14,38$ e $2011=14,83)$

A precipitação pluviométrica efetiva durante as fases I e II do ano de 2010 correspondem a 5,26 $\mathrm{mm}$ e 9,12 mm, respectivamente, totalizando 14,38 mm. Em 2011, a precipitação efetiva foi de $5,19 \mathrm{~mm}$ e $9,64 \mathrm{~mm}$ nas fases I e II, respectivamente, totalizando $14,83 \mathrm{~mm}$. As precipitações pluviométricas no primeiro experimento ocorreram durante a fase vegetativa e final de floração. Já no segundo experimento, as precipitações pluviométricas se concentraram, principalmente, no início do terceiro trifólio da fase vegetativa e final do enchimento de grãos.

A temperatura média mensal para os meses de abril, maio, junho e julho de 2010 foram de 23,$31 ; 18,74 ; 19,01$ e $19,89{ }^{\circ} \mathrm{C}$ respectivamente e de 16,$78 ; 15,89 ; 18,39 ; 18,94$ e $13,75^{\circ} \mathrm{C}$ para os meses de maio, junho, julho, agosto e setembro, respectivamente no ano de 2011.

No primeiro ano, a temperatura mínima não foi inferior a $15{ }^{\circ} \mathrm{C}$ nas fases I e II. De maneira geral, os valores ficaram dentro da faixa recomendada por Silva \& Ribeiro (2009), os quais indicam como valores ideais da temperatura do ar mínima, média e máxima, $12^{\circ} \mathrm{C}, 21^{\circ} \mathrm{C}$ e $29^{\circ} \mathrm{C}$, respectivamente.

No segundo ano, a temperatura mínima chegou a ficar abaixo de $15^{\circ} \mathrm{C}$ durante o florescimento e o enchimento de grãos, interferindo no ciclo da cultura. Em consequência da baixa temperatura, os tratamentos com redução da lâmina de $40 \%, 60 \%$ e $80 \%$ na fase II, apresentaram menor ciclo em relação ao tratamento que foi mantido sem restrição hídrica.

$\mathrm{Na}$ Tabela 2, encontra-se um resumo da análise de variância, para os teores nutricionais de nitrogênio, fósforo, potássio, cálcio, magnésio, enxofre, boro, cobre e ferro no primeiro e segundo experimentos. A interação tratamentos x lâminas de irrigação apresentou significância para enxofre e ferro para o primeiro e segundo anos. A interação tratamentos $\mathrm{x}$ 
lâminas de irrigação não apresentou significância para nitrogênio, fósforo, potássio, cálcio, magnésio, boro e cobre.

Tabela 2. Valores de F e nível de significância obtido na análise de variância na cultura do feijoeiro submetida a diferentes combinações de lâminas aplicada.

\begin{tabular}{|c|c|c|c|c|c|c|}
\hline Fonte de variação & $\mathbf{A}$ & B & AxB & trat/test & anos & CV (\%) \\
\hline \multicolumn{7}{|l|}{ Nitrogênio } \\
\hline 2010 & $0,49^{\mathrm{ns}}$ & $2,58^{\mathrm{ns}}$ & $0,68^{\mathrm{ns}}$ & $1,82^{*}$ & \multirow[t]{2}{*}{$53,96^{*}$} & 9,68 \\
\hline 2011 & $1,75^{\mathrm{ns}}$ & $1,16^{\mathrm{ns}}$ & $0,81^{\mathrm{ns}}$ & $1,13^{*}$ & & 8,43 \\
\hline \multicolumn{7}{|l|}{ Fósforo } \\
\hline 2010 & $2,00^{\mathrm{ns}}$ & $3,18^{*}$ & $0,57^{\mathrm{ns}}$ & $1,82^{*}$ & \multirow[t]{2}{*}{$81,29^{*}$} & 8,57 \\
\hline 2011 & $6,62^{*}$ & $0,69^{\mathrm{ns}}$ & $1,37^{\mathrm{ns}}$ & $1,49^{*}$ & & 9,11 \\
\hline \multicolumn{7}{|l|}{ Potássio } \\
\hline 2010 & $1,78^{\mathrm{ns}}$ & $0,81^{\mathrm{ns}}$ & $0,83^{\mathrm{ns}}$ & $0,92^{*}$ & \multirow[t]{2}{*}{$365,42^{*}$} & 11,3 \\
\hline 2011 & $0,28^{\mathrm{ns}}$ & $1,41^{\mathrm{ns}}$ & $0,82^{\mathrm{ns}}$ & $0,76^{*}$ & & 10,83 \\
\hline \multicolumn{7}{|l|}{ Cálcio } \\
\hline 2010 & $0,20^{\mathrm{ns}}$ & $1,83^{\mathrm{ns}}$ & $1,73^{\mathrm{ns}}$ & $1,01^{*}$ & \multirow[t]{2}{*}{$10,19^{*}$} & 11,66 \\
\hline 2011 & $0,28^{\mathrm{ns}}$ & $1,50^{\mathrm{ns}}$ & $1,40^{\mathrm{ns}}$ & $0,81^{*}$ & & 15,71 \\
\hline \multicolumn{7}{|l|}{ Magnésio } \\
\hline 2010 & $0,51^{\mathrm{ns}}$ & $5,52^{*}$ & $1,58^{\mathrm{ns}}$ & $1,95^{\mathrm{ns}}$ & \multirow[t]{2}{*}{$249,15^{*}$} & 7,68 \\
\hline 2011 & $0,51^{\mathrm{ns}}$ & $1,29^{\mathrm{ns}}$ & $1,11^{\mathrm{ns}}$ & $4,12^{\mathrm{ns}}$ & & 12,18 \\
\hline \multicolumn{7}{|l|}{ Enxofre } \\
\hline 2010 & $15,38^{*}$ & $4,55^{*}$ & $4,26^{*}$ & $6,23^{\mathrm{ns}}$ & \multirow[t]{2}{*}{$80,35^{*}$} & 20,00 \\
\hline 2011 & $8,99^{*}$ & $0,60^{\mathrm{ns}}$ & $1,53^{\mathrm{ns}}$ & $1,45^{*}$ & & 23,42 \\
\hline \multicolumn{7}{|l|}{ Boro } \\
\hline 2010 & $0,23^{\mathrm{ns}}$ & $1,30^{\mathrm{ns}}$ & $0,93^{\mathrm{ns}}$ & $0,32^{*}$ & \multirow[t]{2}{*}{$0,03^{\mathrm{ns}}$} & 14,64 \\
\hline 2011 & $4,26^{*}$ & $0,18^{\mathrm{ns}}$ & $3,14^{\mathrm{ns}}$ & $2,87^{\mathrm{ns}}$ & & 5,25 \\
\hline \multicolumn{7}{|l|}{ Cobre } \\
\hline 2010 & $0,95^{\mathrm{ns}}$ & & $1,05^{\mathrm{ns}}$ & $1,18^{*}$ & \multirow[t]{2}{*}{$2,63^{\mathrm{ns}}$} & 12,9 \\
\hline 2011 & $0,35^{\mathrm{ns}}$ & $1,19^{\mathrm{ns}}$ & $0,54^{\mathrm{ns}}$ & $0,39^{*}$ & & 24,72 \\
\hline \multicolumn{7}{|l|}{ Ferro } \\
\hline 2010 & $15,40^{*}$ & $15,98^{*}$ & $8,95^{*}$ & $16,67^{\mathrm{ns}}$ & \multirow[t]{2}{*}{$265,85^{*}$} & 9,1 \\
\hline 2011 & $2,74^{*}$ & $3,23^{*}$ & $2,57^{*}$ & $2,03^{*}$ & & 23,42 \\
\hline
\end{tabular}

Nota: * e ns são, respectivamente, significativo a $5 \%$ e não significativo, pelo teste de $\mathrm{F}$. A letra a corresponde ao fator da primeira fase e $b$ o fator da segunda fase. Assim al, corresponde a 40\%; a2 60\%; a3 80 e a4 100\%. e b1 corresponde: $40 \%$; b2 60\%; b3 80\% e b4 $100 \%$ respectivamente.

Os teores de ferro nos grãos variaram entre 341 a 611 e 156 a $257 \mathrm{mg} \mathrm{kg}^{-1}$ no primeiro e segundo anos de cultivo, respectivamente (Tabela 3). Estes resultados foram superiores aos teores médios obtidos em grãos de feijão comerciais ( 88 e de $100 \mathrm{mg} \mathrm{kg}^{-1}$ ) para o primeiro e segundo anos, respectivamente (Pereira et al., 2011). Estes autores verificaram que a cultivar BRS - Valente apresentou médias de 88,0 e 132,0 para o primeiro ano e segundo anos, respectivamente, sendo que essas médias diferiram entre anos, enquanto as médias das demais cultivares comerciais IPR - 88 Uirapuru, Pérola, IAPAR 81 e BAF 110 "Guará" não foram significativas entre anos. 
Tabela 3. Teor de ferro em grãos, nas diferentes combinações de lâminas de irrigação no ciclo da cultura.

\begin{tabular}{|c|c|c|c|c|c|}
\hline \multicolumn{2}{|r|}{2010} & \multicolumn{4}{|c|}{ Ferro $\left(\mathrm{mg}^{\prime} \mathrm{kg}^{-1}\right)$} \\
\hline \multicolumn{2}{|c|}{ Fases $\left(a^{*} b\right)$} & \multicolumn{4}{|c|}{ Fase - II } \\
\hline \multirow{5}{*}{ 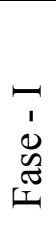 } & $(\%)$ & 40 & 60 & 80 & 100 \\
\hline & 40 & $251,50 \mathrm{aA}$ & $206,50 \mathrm{aB}$ & $237,00 \mathrm{aAB}$ & $191,50 \mathrm{~B}$ \\
\hline & 60 & $251,25 \mathrm{aA}$ & $157,75 \mathrm{cB}$ & $190,50 \mathrm{bB}$ & $186,00 \mathrm{~B}$ \\
\hline & 80 & $176,75 \mathrm{bB}$ & $167,25 \mathrm{cbB}$ & $204,75 \mathrm{aA}$ & $257,00 \mathrm{AB}$ \\
\hline & 100 & $197,50 \mathrm{bB}$ & $196,25 \mathrm{baB}$ & $238,50 \mathrm{aA}$ & $196,00 \mathrm{~B}$ \\
\hline & 2011 & \multicolumn{4}{|c|}{$\begin{array}{c}\text { Ferro }\left(\mathrm{mg.kg}^{-1}\right) \\
\end{array}$} \\
\hline \multicolumn{2}{|c|}{ Fases $(a * b)$} & \multicolumn{4}{|c|}{ Fase - II } \\
\hline \multirow{5}{*}{ 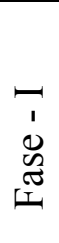 } & $(\%)$ & 40 & 60 & 80 & 100 \\
\hline & 40 & $377,25 \mathrm{~B}$ & $607,00 \mathrm{Aa}$ & $417,50 \mathrm{AB}$ & $453,50 \mathrm{ABab}$ \\
\hline & 60 & $390,50 \mathrm{C}$ & $598,25 \mathrm{BAa}$ & $403,75 \mathrm{CB}$ & $611,25 \mathrm{Aa}$ \\
\hline & 80 & 341,25 & $394,50 \mathrm{~b}$ & 422,50 & $463,00 \mathrm{ab}$ \\
\hline & 100 & 449,75 & $348,00 \mathrm{~b}$ & 470,50 & $411,75 \mathrm{~b}$ \\
\hline
\end{tabular}

Nota: Médias seguidas pelas mesmas letras minúsculas na vertical não diferem entre si; médias seguidas pelas letras maiúsculas na horizontal não diferem entre si.

Os teores de enxofre nos grãos, para o ano de 2010, não foram significativos para as fases I e II. No segundo ano de cultivo, variaram entre 1,8 a $2,4 \mathrm{~g} \mathrm{~kg}^{-1}$ para fase I e não diferiram na segunda fase, conforme apresentado na (Tabela 4). Estes resultados foram semelhantes aos obtidos por Buratto (2012) em cultivares de feijão comum, com valores médios de 2,6 $\mathrm{g} \mathrm{kg}^{-1}$ referente à safra de 2009, em Ponta Grossa, Paraná.

Tabela 4. Teor de enxofre em grãos, nas diferentes combinações de lâminas de irrigação no ciclo da cultura.

\begin{tabular}{|c|c|c|c|c|c|}
\hline \multicolumn{2}{|c|}{2010} & \multicolumn{4}{|c|}{ Enxofre $\left(\mathrm{g} \mathrm{kg}^{-1}\right)$} \\
\hline \multicolumn{2}{|c|}{ Fases $\left(a^{*} b\right)$} & \multicolumn{4}{|c|}{ Fase - II (florescimento a maturação fisiológica) } \\
\hline \multirow{5}{*}{ 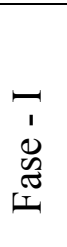 } & $(\%)$ & 40 & 60 & 80 & 100 \\
\hline & 40 & $1,9 \mathrm{c}$ & 2,0 & $2,0 \mathrm{~b}$ & $1,9 \mathrm{~b}$ \\
\hline & 60 & $1,8 \mathrm{cB}$ & $1,9 \mathrm{AB}$ & $2,1 \mathrm{abA}$ & $1,8 \mathrm{bAB}$ \\
\hline & 80 & $2,2 \mathrm{bAB}$ & $2,0 \mathrm{~B}$ & $2,3 \mathrm{aA}$ & $2,0 \mathrm{abB}$ \\
\hline & 100 & $2,4 \mathrm{aA}$ & $2,1 \mathrm{~B}$ & $2,0 \mathrm{bB}$ & $2,2 \mathrm{aAB}$ \\
\hline
\end{tabular}

Nota: Médias seguidas pelas mesmas letras minúsculas na vertical não diferem entre si; médias seguidas pelas letras maiúsculas na horizontal não diferem entre si.

Os resultados obtidos mostram que a deficiência hídrica, ocorrida durante a fase II, teve influência na redução do teor de nitrogênio e magnésio, pois a menor lâmina aplicada durante essa fase resultou em menores médias para os teores de nitrogênio e magnésio (Tabela 5).

Os teores de nitrogênio nos grãos, no segundo ano de cultivo, foram influenciados pelas variações das lâminas na fase II, onde as médias foram de 29,8 a $32,7 \mathrm{~g} \mathrm{~kg}^{-1}$. Estes resultados foram inferiores aos obtidos por Pereira et al. (2011), que verificaram média de 44,6 e $35,0 \mathrm{~g} \mathrm{~kg}^{-1}$, para o primeiro e segundo anos, respectivamente, para a cultivar comercial Pérola. 
Os teores de magnésio nos grãos variaram entre 3,8 a 4,2 $\mathrm{g} \mathrm{kg}^{-1}$ no segundo ano de cultivo, para as fases I e II, respectivamente. Estes resultados foram superiores aos obtidos por Pereira et al. (2011), que verificaram média de 2,00 e $1,07 \mathrm{~g} \mathrm{~kg}^{-1}$, para o primeiro e segundo anos, respectivamente, para a cultivar comercial Pérola.

Tabela 5. Teores de magnésio e proteína total em grãos, nas diferentes combinações de lâminas de irrigação durante o ciclo do feijoeiro referente ao ano 2010.

\begin{tabular}{|c|c|c|}
\hline Lâmina (mm) & Nitrogênio $\left(\mathrm{g} \mathrm{kg}^{-1}\right)$ & Magnésio $\left(\mathrm{g} \mathrm{kg}^{-1}\right)$ \\
\hline ano & 2010 & 2010 \\
\hline \multicolumn{3}{|c|}{ Fase - I (emergência ao pleno florescimento) } \\
\hline $40 \%$ & 31,4 & 4,0 \\
\hline $60 \%$ & 30,7 & 3,9 \\
\hline $80 \%$ & 32,0 & 4,0 \\
\hline $100 \%$ & 31,3 & 4,0 \\
\hline \multicolumn{3}{|c|}{ Fase - II (florescimento a maturação fisiológica) } \\
\hline $40 \%$ & $31,1 \mathrm{ab}$ & $3,9 \mathrm{ab}$ \\
\hline $60 \%$ & $29,8 \mathrm{~b}$ & $3,8 \mathrm{~b}$ \\
\hline $80 \%$ & $31,8 \mathrm{ab}$ & $4,1 \mathrm{a}$ \\
\hline $100 \%$ & $32,7 \mathrm{a}$ & $4,2 \mathrm{a}$ \\
\hline
\end{tabular}

Nota: Médias seguidas pelas mesmas letras minúsculas na vertical não diferem entre si; médias seguidas pelas letras maiúsculas na horizontal não diferem entre si.

Os resultados obtidos mostram que a deficiência hídrica ocorrida durante a fase I, teve influência na redução do teor de fósforo, pois o menor volume de água aplicada durante essa fase (maior a deficiência hídrica) gerou menores médias nos teores de fósforo. Os teores médios de fósforo na segunda fase não diferiram entre os tratamentos avaliados (Tabela 6).

Tabela 6. Teor de fósforo e boro em grãos, nas diferentes combinações de lâminas de irrigação durante o ciclo do feijoeiro referente ao ano de 2011.

\begin{tabular}{|c|c|c|}
\hline Lâmina (mm) & Fósforo $\left(\mathrm{g} \mathrm{kg}^{-1}\right)$ & Boro $\left(\mathrm{mg} \mathrm{kg}^{-1}\right)$ \\
\hline ano & 2011 & 2011 \\
\hline \multicolumn{3}{|c|}{ Fase - I (emergência ao pleno florescimento) } \\
\hline $40 \%$ & $3,2 \mathrm{c}$ & $36,4 \mathrm{ab}$ \\
\hline $60 \%$ & $3,3 \mathrm{bc}$ & $35,9 \mathrm{~b}$ \\
\hline $80 \%$ & $3,6 \mathrm{a}$ & $37,7 \mathrm{ab}$ \\
\hline $100 \%$ & $3,4 \mathrm{ab}$ & 37,9 a \\
\hline \multicolumn{3}{|c|}{ Fase - II (florescimento a maturação fisiológica) } \\
\hline $40 \%$ & 3,3 & 36,7 \\
\hline $60 \%$ & 3,3 & 37,6 \\
\hline $80 \%$ & 3,4 & 36,9 \\
\hline $100 \%$ & 3,4 & 36,7 \\
\hline
\end{tabular}

Nota: Médias seguidas pelas mesmas letras minúsculas na vertical não diferem entre si; médias seguidas pelas letras maiúsculas na horizontal não diferem entre si.

Os teores de fósforo nos grãos variaram entre 3,2 a $3,6 \mathrm{~g} \mathrm{~kg}^{-1}$ no segundo ano de cultivo, para as fases I e II, respectivamente. Estes resultados foram superiores aos teores 
médios obtidos em grãos de feijão $\left(5,31\right.$ e 4,46 $\left.\mathrm{mg} \mathrm{kg}^{-1}\right)$ para o primeiro e segundo anos de cultivo, respectivamente, para o cultivar comercial Pérola (Pereira et al., 2011). Estes autores verificaram que a cultivar Uirapuru não diferiu entre o primeiro e segundo anos de cultivo, com valores de 4,17 e 4,41 $\mathrm{g} \mathrm{kg}^{-1}$.

Os teores de boro nos grãos variaram entre 35,9 a $37,9 \mathrm{mg} \mathrm{kg}^{-1}$ no segundo ano de cultivo. Estes resultados foram superiores aos obtidos por Ribeiro et al. (2008) em cultivares de feijão de cores com valores médios de $8,27 \mathrm{mg} \mathrm{kg}^{-1}$ observados em dois ambientes.

Thung e Oliveira (1998) mencionam que as plantas e as sementes do feijoeiro obtidas com diferentes práticas culturais diferem no teor de nutrientes.

As médias dos teores dos macronutrientes (nitrogênio, fósforo, potássio, cálcio, magnésio e ferro) no segundo ciclo, diferiram entre os dois anos de cultivo. A diferença entre $\mathrm{o}$ teor de nitrogênio, $\mathrm{kg} \mathrm{ha}^{-1}$ para o primeiro e segundo ciclos, foi significativa para os tratamentos $\mathrm{T}_{1}, \mathrm{~T}_{2}, \mathrm{~T}_{5}, \mathrm{~T}_{6}, \mathrm{~T}_{7}, \mathrm{~T}_{9}, \mathrm{~T}_{10}, \mathrm{~T}_{11}, \mathrm{~T}_{14}$, com valores de $(30,08$ e 35,$19 ; 30,01$ e 36,45 ; 29,14 e 35,$88 ; 33,50$ e 34,$76 ; 33,95$ e 34,$65 ; 32,69$ e 35,$82 ; 32,39$ e 37,$40 ; 30,08$ e $36,03 \mathrm{~g} \mathrm{~kg}^{-}$ ${ }^{1}$ para o ano de 2010 e 2011, respectivamente. Com teores superiores de nitrogênio no segundo ciclo em relação ao primeiro. Enquanto que nos demais tratamentos não houve diferença. Os teores de fósforo, potássio, cálcio, magnésio e ferro foram significativos entre os anos de cultivo, sendo as médias superiores para o segundo ciclo em relação ao primeiro ano. A diferença entre o teor de Cálcio, $\mathrm{g} \mathrm{kg}^{-1}$ para o primeiro e segundo ciclos, foi significativa para os tratamentos $\mathrm{T}_{2}, \mathrm{~T}_{7}, \mathrm{~T}_{10}, \mathrm{~T}_{11}, \mathrm{~T}_{16}$, com valores de $(11,00 \mathrm{e} 14,05 ; 12,75 \mathrm{e}$ 14,$10 ; 12,25$ e 14,$43 ; 13,00$ e 16,$70 ; 11,00$ e 14,53) $\mathrm{g} \mathrm{kg}^{-1}$ para o ano de 2010 e 2011, respectivamente. Enquanto que nos demais tratamentos não houve diferença. Com teores superiores de Cálcio no segundo ciclo, em relação ao primeiro. A diferença entre o teor de Boro, $\mathrm{mg} \mathrm{kg}^{-1}$ para o primeiro e segundo ciclos, foi significativa para os tratamentos $\mathrm{T}_{15}$, com valores de $(32,75$ e 39,92$)$ para o ano de 2010 e 2011, respectivamente. Enquanto que nos demais tratamentos não houve diferença. A diferença entre o teor de Cobre, $\mathrm{mg} \mathrm{kg}^{-1}$ para o primeiro e segundo ciclos, foi significativa para os tratamentos $\mathrm{T}_{6}, \mathrm{~T}_{15}, \mathrm{~T}_{16}$, com valores de $(10,00$ e 15,$00 ; 10,75$ e 14,$50 ; 10,25$ e 14,75$)$ para o ano de 2010 e 2011, respectivamente. Enquanto que nos demais tratamentos não houve diferença. Uma das explicações desses maiores valores dos teores fósforo, potássio, cálcio, magnésio e ferro, está relacionado à melhoria das características químicas do solo no segundo ano em relação ao primeiro ano.

Pereira et al. (2011) obtiveram menores médias para os teores de macronutrientes e micronutrientes entre os dois ciclos. Estes autores mencionam que as variações são devidas às diferentes condições climáticas durante os períodos de florescimento e formação de vagens. No segundo ano, durante o início da formação das vagens, observou-se alta precipitação e temperatura próxima aos $20{ }^{\circ} \mathrm{C}$. No primeiro ano, a fase de florescimento coincidiu com déficit hídrico e maiores oscilações de temperatura.

Tanto o estresse hídrico quanto a alta temperatura durante o período de enchimento de grãos, podem ser a explicação para as variações na concentração de proteínas, tanto entre locais, como entre anos em um mesmo local (Rangel et al., 2007).

$\mathrm{Na}$ Tabela 7, encontra-se um resumo da análise de variância para o acúmulo dos teores nutricionais de nitrogênio, fósforo, potássio, cálcio, magnésio, enxofre, boro e cobre para o segundo ciclo. 
Tabela 7. Valores de F e nível de significância obtido na análise de variância submetida a diferentes combinações de lâminas no acúmulo de nutrientes em grãos de feijão no ano de 2011.

\begin{tabular}{lcccc}
\hline Fonte de variação & $\mathbf{A}$ & $\mathbf{B}$ & $\mathbf{A x B}$ & $\mathbf{C V} \mathbf{( \% )}$ \\
\hline Nitrogênio & $1,16^{\mathrm{ns}}$ & $9,74^{*}$ & $1,24^{\mathrm{ns}}$ & 15,01 \\
Fósforo & $4,54^{*}$ & $9,66^{*}$ & $0,74^{\mathrm{ns}}$ & 15,27 \\
Potássio & $1,01^{\mathrm{ns}}$ & $7,50^{*}$ & $0,79^{\mathrm{ns}}$ & 15,24 \\
Cálcio & $0,72^{\mathrm{ns}}$ & $8,43^{*}$ & $1,10^{\mathrm{ns}}$ & 21,13 \\
Enxofre & $3,36^{*}$ & $6,33^{*}$ & $1,66^{\mathrm{ns}}$ & 16,29 \\
Boro & $1,58^{\mathrm{ns}}$ & $11,61^{*}$ & $0,84^{\mathrm{ns}}$ & 14,33 \\
Cobre & $1,40^{\mathrm{ns}}$ & $6,17^{*}$ & $0,99^{\mathrm{ns}}$ & 26,67 \\
\hline
\end{tabular}

Nota: * e ns são, respectivamente, significativo a 5\% e não significativo, pelo teste de $\mathrm{F}$.

A quantidade de nitrogênio acumulado em grãos variou com as diferentes lâminas de irrigação para a fase II, no entanto, não foi significativa para a fase I. $\mathrm{O}$ acúmulo de nitrogênio nos grãos variou entre $86,15 \mathrm{a} 113,34 \mathrm{~kg} \mathrm{ha}^{-1}$ para o segundo ano de cultivo (Tabela 8). Estes resultados foram semelhantes aos obtidos por Ciancio (2010), com média de 80,37 kg ha ${ }^{-1}$ para o tratamento com adubação recomendada pela CQFS RS/SC (2004), sendo estes similares aos resultados obtidos por Pessoa et al. (1996) com médias de 33,4 e 103,3 $\mathrm{kg} \mathrm{ha}^{-1}$ para o tratamento não irrigado e irrigado, respectivamente, uma vez que os autores verificaram diferenças entre as condições estudadas. Entretanto, Ramos Júnior (2006) trabalhando com doses de fósforo em cultivares de feijão carioca precoce, observou que o acúmulo de nitrogênio foi de $31,4 \mathrm{~kg} \mathrm{ha}^{-1}$, em Botucatu, SP.

A quantidade de potássio acumulado em grãos variou com as diferentes lâminas de irrigação na fase II, não sendo significativa para a fase I (Tabela 8). O acúmulo de potássio nos grãos variou entre 92,95 a 118,61 kg ha ${ }^{-1}$ no segundo ano de cultivo. Entretanto, estes resultados foram superiores aos obtidos por Ciancio (2010), com média de 77,89 kg ha-1 para o tratamento com adubação recomendada pela CQFS RS/SC (2004), e, aos resultados obtidos por Pessoa et al. (1996) com médias de 7,5 e 30,4 $\mathrm{kg} \mathrm{ha}^{-1}$, para o tratamento não irrigado e irrigado, respectivamente, com diferenças entre as condições estudadas.

Tabela 8. Acúmulo dos macronutrientes nitrogênio, potássio, cálcio, fósforo e enxofre ( $\mathrm{kg} \mathrm{ha}{ }^{-}$ ${ }^{1}$ ), extraídos em grãos de feijão IAC-Alvorada, segundo ciclo.

\begin{tabular}{cccccc}
\hline $\begin{array}{c}\text { Lâmina } \\
(\mathbf{m m})\end{array}$ & Nitrogênio & Potássio & $\begin{array}{c}\text { Cálcio } \\
\text { kg ha }\end{array}$ & Fósforo & Enxofre \\
\hline Ano & \multicolumn{5}{c}{2011} \\
\hline \multicolumn{5}{c}{ Fase - I (emergência ao pleno florescimento) } \\
\hline $40 \%$ & 99,53 & 103,41 & 39,06 & $8,85 \mathrm{~b}$ & $7,63 \mathrm{~b}$ \\
$60 \%$ & 101,37 & 112,49 & 42,30 & $9,71 \mathrm{ab}$ & $8.33 \mathrm{ab}$ \\
$80 \%$ & 107,70 & 110,80 & 43,26 & $10,70 \mathrm{a}$ & $8,63 \mathrm{ab}$ \\
$100 \%$ & 107,58 & 111,75 & 42,63 & $10,39 \mathrm{a}$ & $9,14 \mathrm{a}$ \\
\hline \multicolumn{7}{c}{ Fase - II (florescimento a maturação fisiológica) } \\
\hline $40 \%$ & $86,15 \mathrm{~b}$ & $92,95 \mathrm{~b}$ & $32,69 \mathrm{~b}$ & $8,19 \mathrm{~b}$ & $7,15 \mathrm{~b}$ \\
$60 \%$ & $107,33 \mathrm{a}$ & $111,82 \mathrm{a}$ & $42,10 \mathrm{a}$ & $10,05 \mathrm{a}$ & $8,69 \mathrm{a}$ \\
$80 \%$ & $109,37 \mathrm{a}$ & $118,61 \mathrm{a}$ & $45,52 \mathrm{a}$ & $10,58 \mathrm{a}$ & $8,84 \mathrm{a}$ \\
$100 \%$ & $113,34 \mathrm{a}$ & $115,61 \mathrm{a}$ & $46,95 \mathrm{a}$ & $10,76 \mathrm{a}$ & $9,04 \mathrm{a}$ \\
\hline
\end{tabular}


Nota: Médias seguidas pelas mesmas letras minúsculas na vertical não diferem entre si; médias seguidas pelas letras maiúsculas na horizontal não diferem entre si.

A quantidade de cálcio acumulado em grãos variou com as diferentes lâminas de irrigação na fase II e não foi significativa para a fase I (Tabela 8). O acúmulo de cálcio nos grãos variou entre 32,69 a $46,95 \mathrm{~kg} \mathrm{ha}^{-1}$ no segundo ano de cultivo. Estes resultados foram inferiores aos obtidos por Ciancio (2010), com média de $56,62 \mathrm{~kg} \mathrm{ha}^{-1}$ para o tratamento com adubação recomendada pela CQFS RS/SC (2004).

A quantidade de fósforo acumulado em grãos variou com as diferentes lâminas de irrigação nas fases I e II (Tabela 8). O acúmulo de fósforo nos grãos variou entre 8,19 a 10,76 $\mathrm{kg} \mathrm{ha}^{-1}$ no segundo ano de cultivo. Estes resultados foram semelhantes aos obtidos por Ciancio (2010), com médias de 11,89 e $10,32 \mathrm{~kg} \mathrm{ha}^{-1}$ para o tratamento com adubação recomendada pela CQFS RS/SC (2004) e, controle, respectivamente. No feijão comum, o valor de $\mathrm{P}$ acumulado foi de $10 \mathrm{~kg} \mathrm{ha}^{-1}$ em solo de várzea (FAGERIA; SANTOS, 1998). Entretanto, estes resultados foram inferiores aos obtidos por Pessoa et al. (1996), com médias de 8,0 e $18,8 \mathrm{~kg} \mathrm{ha}^{-1}$ para o tratamento não irrigado e irrigado, respectivamente. Ramos Júnior (2006) trabalhando com doses de fósforo em cultivares de feijão carioca precoce, observou que o acúmulo de fósforo foi de $3,17 \mathrm{~kg} \mathrm{ha}^{-1}$, em Botucatu, SP.

A quantidade de enxofre acumulado em grãos variou com as diferentes lâminas de irrigação nas fases I e II. O acúmulo de enxofre nos grãos variou entre 7,15 a 9,14 kg ha ${ }^{-1}$ no segundo ano de cultivo. Estes resultados foram semelhantes aos obtidos por Ciancio (2010), com médias de 11,89 e $10,32 \mathrm{~kg} \mathrm{ha}^{-1}$ para o tratamento com adubação recomendada pela CQFS RS/SC (2004) e, controle, respectivamente. Ramos Júnior (2006), trabalhando com doses de fósforo em cultivares de feijão carioca precoce, observou um acúmulo de enxofre de $3,17 \mathrm{~kg} \mathrm{ha}^{-1}$, em Botucatu, SP.

Tabela 9. Acúmulo de micronutrientes, boro e cobre $\left(\mathrm{g} \mathrm{ha}^{-1}\right)$, extraídos em grãos de feijão IAC-Alvorada.

\begin{tabular}{|c|c|c|}
\hline Lâmina (mm) & Boro $\left(\mathrm{g} \mathrm{ha}^{-1}\right)$ & Cobre $\left(\mathrm{g} \mathrm{ha}^{-1}\right)$ \\
\hline ano & 2011 & 2011 \\
\hline \multicolumn{3}{|c|}{ Fase - I (emergência ao pleno } \\
\hline $40 \%$ & 106 & 35 \\
\hline $60 \%$ & 113 & 40 \\
\hline $80 \%$ & 118 & 41 \\
\hline $100 \%$ & 116 & 43 \\
\hline \multicolumn{3}{|c|}{ Fase - II (florescimento a } \\
\hline $40 \%$ & $94 \mathrm{~b}$ & $30 \mathrm{~b}$ \\
\hline $60 \%$ & $113 \mathrm{a}$ & $40 \mathrm{ab}$ \\
\hline $80 \%$ & $122 \mathrm{a}$ & $42 \mathrm{a}$ \\
\hline $100 \%$ & $125 \mathrm{a}$ & $46 \mathrm{a}$ \\
\hline
\end{tabular}

Nota: Médias seguidas pelas mesmas letras minúsculas na vertical não diferem entre si; médias seguidas pelas letras maiúsculas na horizontal não diferem entre si.

A quantidade de boro e cobre acumulado em grãos variou com as diferentes lâminas de irrigação nas fases I e II. O acúmulo de boro e cobre nos grãos variou entre 94 a $125 \mathrm{~g} \mathrm{ha}^{-1}$ e de 30 a $46 \mathrm{~g} \mathrm{ha}^{-1}$ no segundo ano de cultivo, respectivamente (Tabela 9). Observa-se que o efeito das lâminas aplicadas na fase I não interfere no acúmulo de boro e cobre, mas foram 
significativos na fase II, mostrando que as maiores lâminas aplicadas durante a fase II, resultaram em maiores médias dos mesmos conforme apresentado na Tabela 9.

\section{CONCLUSÕES}

Houve alterações nos teores de macro e micronutrientes com as diferentes lâminas aplicadas;

A interação entre as lâminas nas fases I e II influenciou nos teores de micronutrientes Fe e S em grãos de feijão;

Houve aumento dos teores de $\mathrm{Fe}$ e diminuição dos teores de $\mathrm{Cu}$, Mn e B com a defíciência hídrica em uma das fases;

Os macro e micronutrientes mais extraídos foram N, P, K, Fe, B e Mn;

$\mathrm{O} \mathrm{N}$ e o $\mathrm{P}$ são os nutrientes exportados em maior quantidade pelos grãos.

\section{REFERÊNCIAS BIBLIOGRÁFICAS}

ALLEN, R. G.; PEREIRA L. S.; RAES, D.; SMITH, M. Crop evapotranspiration Guidelines for computing crop water requerimentes. Rome FAO, 1998. 301 p. (FAO Irrigation and Drainage, 56).

ARAÚJO, R. S.; RAVA, C. A.; STONE, L. F.; ZIMMERMANN, M. J. O. Cultura do feijoeiro comum no Brasil. Associação Brasileira para Pesquisa da Potassa e do Fosfato, Piracicaba, Brasil; 1996. 786p.

BARBOSA. F. R.; GONZAGA, A. C. O. Informações técnicas para o cultivo do feijoeirocomum na região central brasileira: 2012-2014. Santo Antônio de Goiás: Embrapa Arroz e Feijão, 2012. 248 p. (Documentos).

BORÉN, A.; CARNEIRO, J. E. S. A cultura In: VIEIRA, C.; PAULA JUNIOR, T. J.; BORÉN, A. (Eds.). Feijão $2^{a}$ edição atualizada e ampliada. Viçosa: UFV, 2008. p. 13 - 18. BURATTO, J. S. Teores de minerais e proteínas em grãos de feijão e estimativas de parâmetros genéticos. 2012. 148 f. Tese (Doutorado em Genética e Melhoramento de Plantas) - Universidade Federal de Lavras, Lavras, 2012.

CEPAGRI. CENTRO DE PESQUISAS METEOROLÓGICAS E CLIMÁTICAS APLICADAS A AGRICULTURA. Clima dos municípios paulistas. Disponível em: $<$ http://www.cpa.unicamp.br>. Acesso em: 13 de novembro de 2010.

CIANCIO, N. H. R. Produção de grãos, matéria seca e acúmulo de nutrientes em culturas submetidas à adubação orgânica e mineral. 2006. 134 f. Dissertação (Mestrado em Ciência do Solo) - Universidade Federal de Santa Catarina, Santa Maria, 2010.

COETZER, L. A. et al. The effect of boron on reproduction in tomato (Lycopersicum esculentum) and bean (Phaseolus vulgaris). Plant Grond, Tydeskr, v.7, n.4, p.212- 217, 1990.

EMBRAPA Centro Nacional de Pesquisa de Solo. Manual de métodos de análise de solo. 2 ed., Rio de Janeiro: Embrapa Solos, 1997, 212 p. 
EMBRAPA. Centro Nacional. Pesquisa em solos. Sistema brasileiro de classificação de Solos. Brasília: Embrapa-SPI; Rio de janeiro: Embrapa solos, 2006. 306p.

MALAVOLTA, E.; VITTI, G. C.; OLIVEIRA, S. A. Avaliação do estado nutricional das plantas: princípios e aplicações. 2.ed. Piracicaba: Potafos, 1997. 319p.

PASTORINI, L. H. et al. Crescimento inicial de feijoeiro submetido a diferentes doses de fósforo em solução nutritiva. Revista Ceres, Viçosa, MG, v. 47, n. 270, p. 219-228, 2000.

PEREIRA, T. et al. Diversidade no teor de nutrientes em grãos de feijão crioulo no Estado de Santa Catarina. Acta Scientiarum Agronomy, Maringá, v.33, n. 3, p. 477-485, 2011.

PESSOA, A. C. S dos et al. Concentração e acumulação de nitrogênio, fosfóro e potássio pelo feijoeiro cultivado sob diferentes níveis de irrigação. Ciência Rural, Santa Maria, v.26, n.1, p. 69-74, 1996.

RAIJ, B. van. et al. Análise química da fertilidade dos solos tropicais. Campinas: IAC, 2001, 285 p.

RAMOS JUNIOR, E. D. Níveis de fósforo e épocas de aplicação de semeadura na extração de nutrientes do cultivar de feijão carioca. 2006. $134 \mathrm{f}$. Tese (Doutorado em Agronomia/Agricultura)-Faculdade de Ciências Agronômicas, Universidade Estadual Paulista, Botucatu, 2006.

RANGEL, M.A.S. et al. Efeitos da interação genótipos x ambientes no rendimento de grãos e nos teores de proteína de cultivares de soja. Acta Scientiarum Agronomy, v. 29, n. 3, p. 351 - 354, 2007.

RIBEIRO, N. D. et al. Composição de microminerais em cultivares de feijão e aplicações para o melhoramento genético. Bragantia, v. 67, n. 2, 267-273, 2008.

RIOS, O. A. et al. Efeito da estocagem e das condições de colheita sobre algumas propriedades físicas, químicas e nutricionais de três cultivares de feijão (Phaseolus vulgaris L.). Ciência e Tecnologia de Alimentos, Campinas, v. 23, p. 34-45, 2003.

SILVA, M. G. et al. Rendimento do feijoeiro irrigado cultivado no inverno em sucessão de culturas, sob diferentes preparos do solo. Acta Scientiarum Agronomy, Maringá, v. 28, n.3, p. 433-439, 2006.

SILVA.C. da.; RIBEIRO. J. R. Zoneamento agroclimático para o feijão ( $2^{\mathbf{a}}$ safra) nos Estado de Goiás, Mato Grosso, Mato Grosso do Sul, Minas Gerais e Bahia . In: KLUTHCOUSKI. J.; STONE. L.F.; AIDAR. H (Org.). Fundamentos para uma agricultura sustentável, com ênfase na cultura do feijoeiro. Santo Antônio de Goiás. EMBRAPA, 2009. p. $97-104$. 
SILVEIRA, P. M. da; BRAZ, A. J. B. P.; DIDONET, A. D. Uso do clorofilômetro como indicador da necessidade de adubação nitrogenada em cobertura no feijoeiro. Pesquisa Agropecuária Brasileira, Brasília, v. 38, n. 9, p. 1083-1087, 2003

THUNG, M. D. T.; OLIVEIRA, I. P. de. Problemas abióticos que afetam a produção do feijoeiro e seus métodos de controle. Santo Antônio de Goiás: EMBRAPA CNPAF, 1998. $172 \mathrm{p}$. 